\title{
Distribution of aerial hazard maps of debris flow on a social network service
}

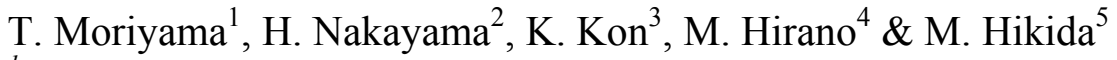 \\ ${ }^{1}$ Department of EcoDesign, Sojo University, Japan \\ ${ }^{2}$ Siesta Club Co. Ltd., Japan \\ ${ }^{3}$ NPO Tanoshii Mogura Club, Japan \\ ${ }^{4}$ NPO Disaster Prevention Network Research Institute, Japan \\ ${ }^{5}$ Dept. of Civil Engineering, Kagoshima College of Technology, Japan
}

\begin{abstract}
Disaster prevention information systems should maintain high levels of reliability for information. Internet Bulletin Board Systems (BBS) occasionally include inaccurate, malicious or incorrect information. Anonymous posts to bulletin boards are particularly unreliable. BBS should not serve as primary means for official communication. Moreover, most local governments are hesitant to issue evacuation orders despite the urgency of timely announcements because of the suddenness of debris flows. In the current study, we developed a disaster prevention information system using a combined Geographic Information System (GIS) and Social Network Service (SNS) called giSight. The function of SNS is to keep the reliability of information at a high level by registering users. A hazard map of landslide and debris flow is indicated on the GIS with high-resolution aerial photograph tile maps. This hazard map identifies the mesh polygon with dangerous conditions in real-time, i.e. dynamically. This system is not only useful for disaster prevention, but is also expected to facilitate the exchange of information by residents in normal circumstances.

Keywords: debris flow, hazard map, critical rainfall, social network service, disaster information system, Geographic Information System.
\end{abstract}

\section{Introduction}

Evacuation of residents is occasionally necessary to prevent the loss of life from debris flow following intense rainfall. However, official evacuation orders by 
local governments are often delayed due to the hesitation of the governmental officer or some human mistakes, and the delayed warnings have resulted severe damage. Consequently, disaster information should be conveyed directly to affected populations as soon as possible.

The current study develops a disaster information system that conveys information directly to residents in rural areas.

\section{Prediction of debris flow using cumulative rainfall amount}

Previous experimental results [1] have indicated that debris flow occurs when surface flow appears on a slope due to heavy rainfall. Solving the momentum and continuity equations for subsurface conditions using the kinematic wave theory, the occurrence conditions for surface flow are derived as

$$
\begin{gathered}
\mathbf{I} \geq \frac{k T \sin \theta}{\lambda}, \\
\lambda D=\int_{0}^{T} r \cos \theta d t
\end{gathered}
$$

where 1 is the length of the slope, $k$ is the hydraulic conductivity, $\theta$ is the angle of slope, $\lambda$ is the porosity, $T$ is the time of concentration, $D$ is the depth of the deposits, and $r$ is the rainfall intensity.

Assuming that debris flow occurs when surface flow appears on a slope, the occurrence criteria for debris flow based on eqn. (1) and eqn. (2) are expressed as

or

$$
\frac{1}{T} \int_{0}^{T} r d t \geq \frac{D k}{\mathbf{I}} \tan \theta
$$

$$
R(t, T)=\int_{t-T}^{T} r(\tau) d \tau \geq \frac{D k}{\mathbf{I}} \tan \theta=R_{c}
$$

where $R$ is the cumulative rainfall amount and $T$ is the time of concentration.

Equation (3) indicates that debris flow will occur when cumulative rainfall within the time of concentration exceeds a certain value related to the properties of the slope. Hirano et al. [2] proposed a system analysis technique to identify parameters to predict the occurrence of debris flow. To estimate the time of concentration $T$ and critical rainfall $R c$, Hirano et al. defined cumulative rainfall $\mathrm{R}(t, \tau)$ as

$$
\begin{gathered}
R_{\max }(\tau)=\max R(t, T) \\
R(t, T)=\int_{t-T}^{T} r(\tau) d \tau \geq \frac{D k}{\mathrm{I}} \tan \theta=R_{c} .
\end{gathered}
$$

The maximum values of $R(t, \tau)$ for each time, $R \max (\tau)$, are plotted against $\tau$. If there are no errors in the data or in the theory, the plotted lines should exceed point $\operatorname{R\operatorname {max}}(T)=R c \quad$ when debris flow occurs, and should fall below the point 
when debris flow does not occur, shown schematically in Figure 1. Consequently, the upper limit line of non-occurrence and the lower limit line of occurrence should cross near point $(T, R c)$, as illustrated in Figure 2(a). Errors in the data as well as in the theory will prevent the intersection of these two curves, which will remain separated as shown in Figure 2(b). The time of concentration is estimated by the point where the difference between two curves is minimized.

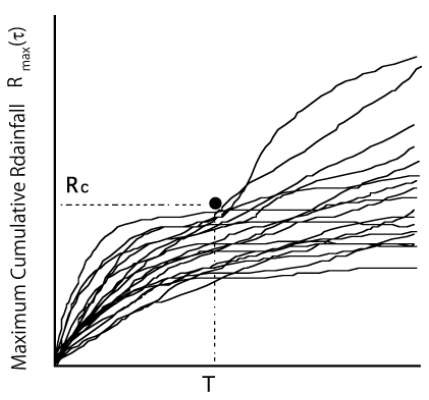

Duration

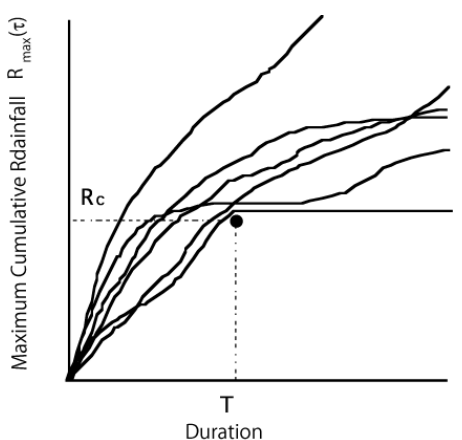

Duration

Figure 1: $\quad$ Lower limit of occurrence and upper limit of non-occurrence.

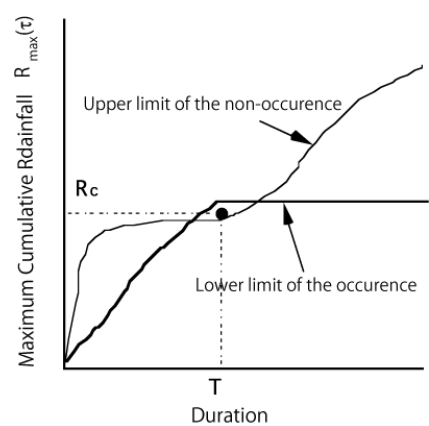

(a) Theoretical lines

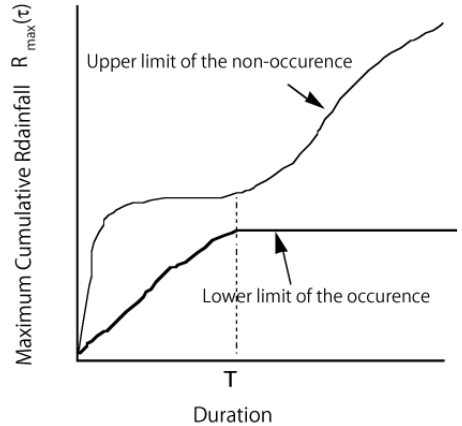

(b) Real lines

Figure 2: Critical lines, maximum cumulative rainfall and concentration time.

\section{Application to actual debris flows}

The data are available for debris flow occurrence in Kagoshima Prefecture in 1969, 1971, 1993 and 1997.

The maximum value $\operatorname{Rmax}(\tau)$ for the cumulative time $\tau$ of each rainfall event is calculated using eqn.(4) and shown in Figure 3. The minimum cumulative rainfall amount for occurrence of debris flow was determined to be $121 \mathrm{~mm}$ for a 3-hour duration and the maximum cumulative rainfall amount of non-occurrence was also $121 \mathrm{~mm}$ for a 3-hour duration [3]. In the same way, the maximum 


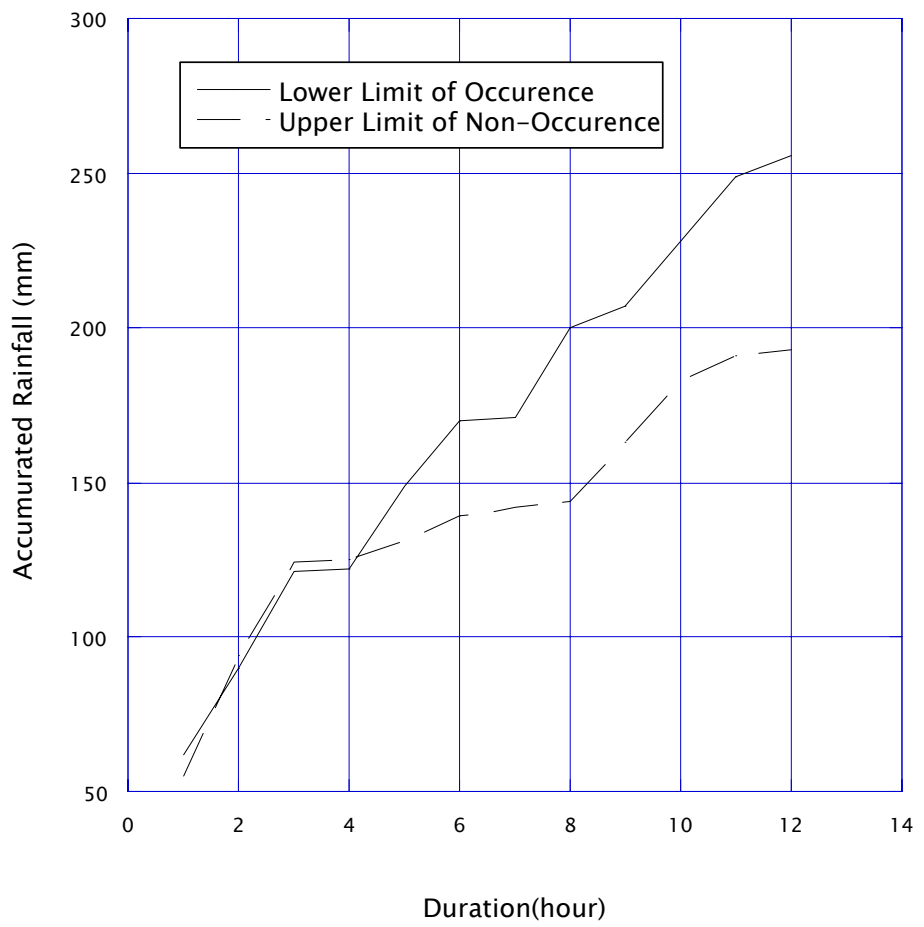

Figure 3: Critical maximum cumulative rainfall for analysis of debris flow in the Akune and Izumi Districts [3] cumulative rainfall for nonoccurrence of a landslide was $88 \mathrm{~mm}$ for a-3 hour duration [3].

cumulative rainfall for non-occurrence of a landslide was $88 \mathrm{~mm}$ for a 3-hour duration [3].

\section{Dynamic hazard map}

Radar data observed by the Ministry of Land, Transportation and Infrastructure of Japan were utilized to develop the dynamic hazard map. The spatial resolution is approximately 1 square $\mathrm{km}$ and the temporal resolution is 5 minutes. The study area includes Kyushu and Shikoku Islands and the Chugoku area of Honshu Island, Japan.

Radar data for heavy rainfall observed from 19 to 23 July 2006 were used. These data are recorded using the XML database "eXist" [4] at the Sojo University laboratory. Using the estimated critical limit for cumulative rainfall defined above, a dynamic hazard map was derived based on the cumulative rainfall amount recorded by the precipitation radar. Figure 4 shows an example of a dynamic hazard map for the Minamata District area observed on 22 July 2006. A concentration time of 3 hours was used to generate the dynamic hazard map in real time. Events with greater than $88 \mathrm{~mm}$ of cumulative rainfall in 


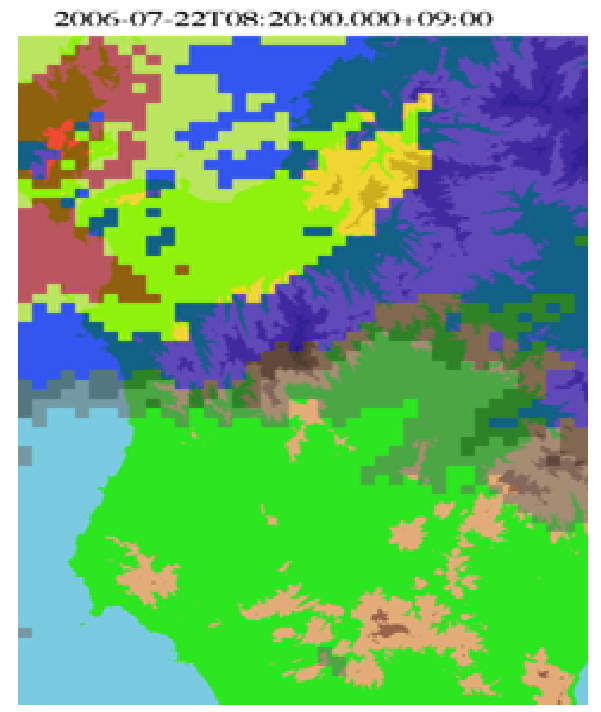

Figure 4: Example of the dynamic hazard map.

3 hours may result in the occurrence of a landslide and rain in excess of $121 \mathrm{~mm}$ in 3 hours indicates the certain occurrence of debris flow. The former is indicated as yellow mesh and the latter is indicated as red mesh on the dynamic hazard map.

Java programming language was used to generate the dynamic hazard map. This program accesses the XML database "eXist" and retrieves rainfall data for three-hour intervals, which are used to calculate cumulative rainfall amounts. The cumulative rainfall values are converted to XML data format, allowing disaster information to be transmitted using the system described in the next chapter.

\section{Dynamic hazard aerial map displayed on social network service}

Disaster prevention information systems should maintain high levels of reliability for information. Internet Bulletin Board Systems (BBS) occasionally include inaccurate, malicious or incorrect information. Anonymous posts to bulletin boards are particularly unreliable. BBS should not serve as primary means for official communication. Moreover, most local governments are hesitant to issue evacuation orders despite the urgency of timely announcements because of the suddenness of debris flows.

Internet social network services (SNS) provide access to users, which must be registered by providing individual information. Consequently, SNS are able to identify the sender of information to some degree and can confirm the reliability of information provided to the network by registered enrollees, in contrast to 
internet BBS. SNS are able to minimize the delay of hazard information transmission by securing the source and reliability of the hazard information posts.

Drupal is a content management platform that allows an individual or community of users to easily publish, manage, and organize a wide variety of content on a website. [5]. Our disaster prevention information system was created using Drupal employing Invite, Buddylist and User Relationships modules to generate a SNS that coordinates registered user information with GIS data. The Flex2 version of Modestmaps is used to develop our GIS system. Modestmaps is a BSD-licensed display and interaction library for tile-based maps in Flash and Flex2 [6]. Flex2 and Drupal exchange the data through the Internet using the Action Message Format (AMF). AMF is a proprietary data format created by Macromedia (now Adobe) and used by different mediums. In the current study, the AMFPHP module of Drupal is used to connect Flash as client side and Drupal as server side for high-speed data exchange.

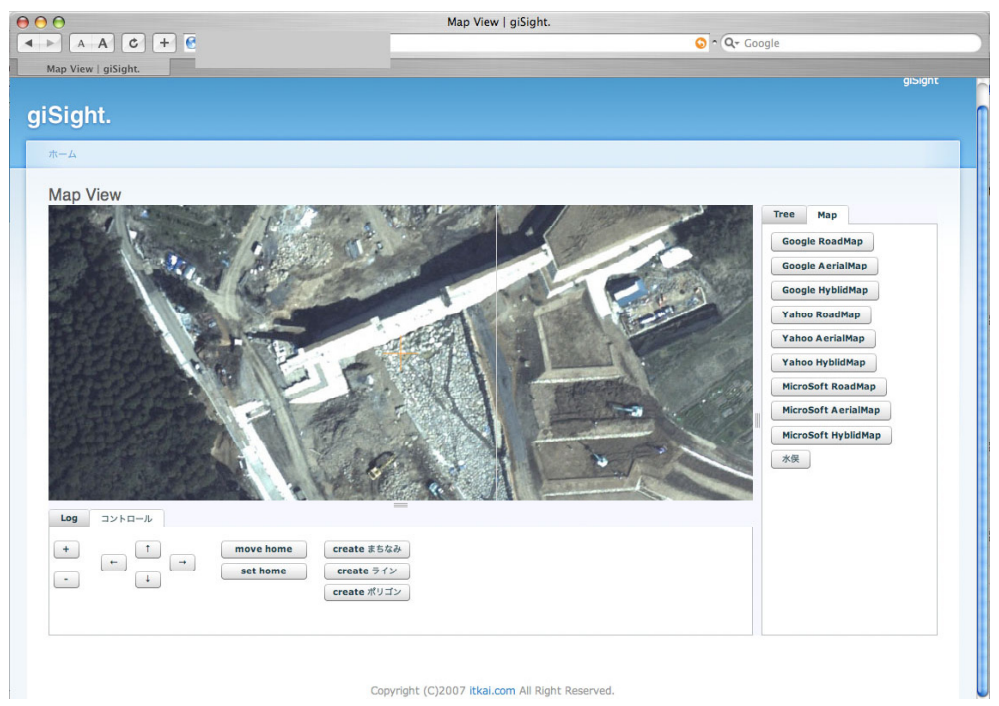

Figure 5: $\quad$ Macro photograph of the barrier to prevent landslides constructed at the site of a debris flow in the Minamata District (highest resolution aerial photograph).

The GIS supported by Flash and Drupal is called "giSight", which displays the tile maps with free scroll, served by Yahoo! Maps or Virtual Earth with Modestmaps. The high-resolution aerial photographs for the Minamata District obtained from Kumamoto Prefecture can also be utilized as tile maps. These tile maps are served by Kumamoto Prefecture and stored on Amazon S3 [7], which is an inexpensive unlimited storage service. The highest resolution of the aerial photographs collected by Kumamoto Prefecture is $20 \mathrm{~cm} /$ pixel. Figure 5 shows a 


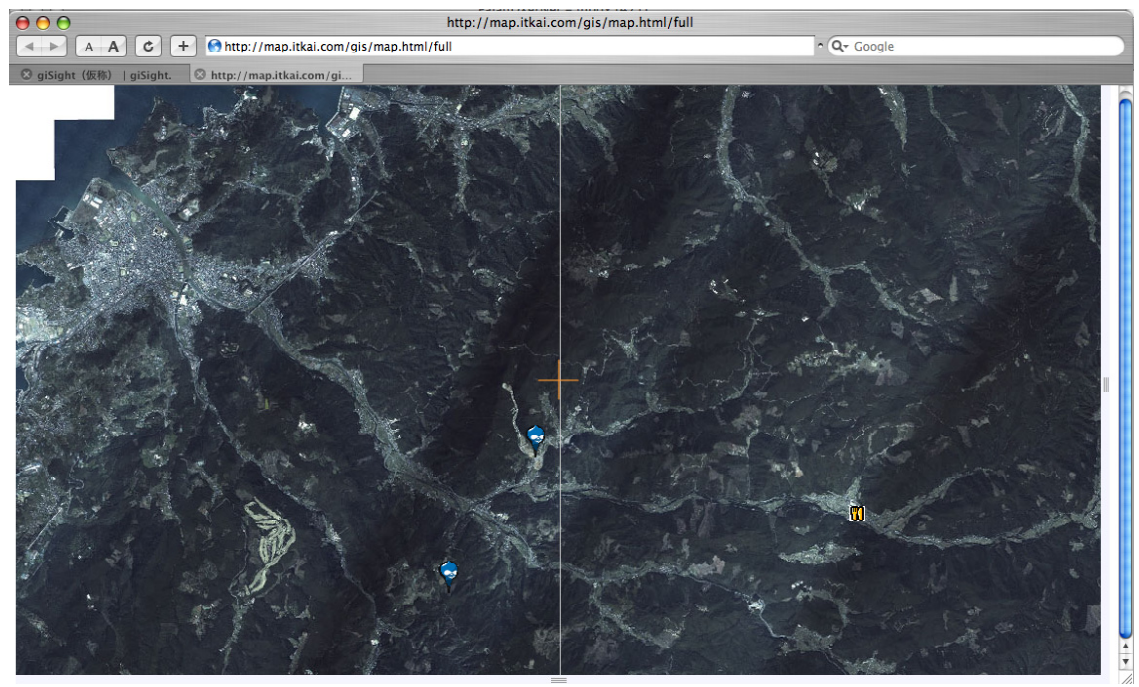

Figure 6: Example of giSight that displays markers for the Minamata District.

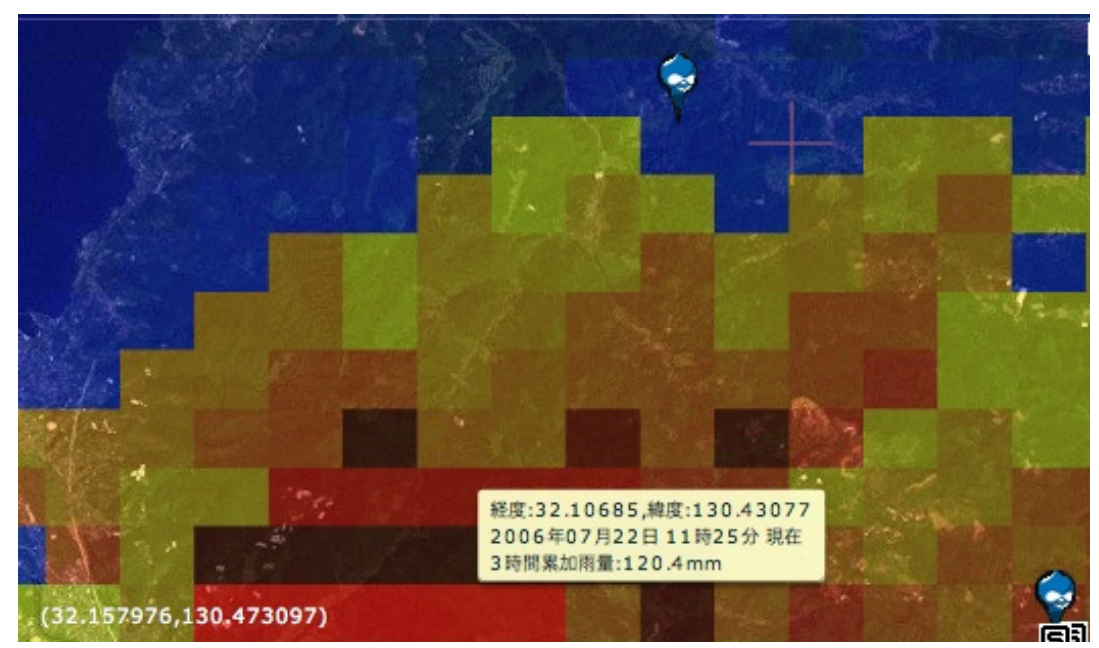

Figure 7: $\quad$ Example of a dynamic hazard map for landslide and debris flow.

macro photograph of a dam constructed to prevent debris flow at the site of a debris flow in the Minamata District on 23 July 2003. Lines and polygons can be added to the map as markers using the Flash client. Figure 6 shows an example of giSight that displays the markers for the Minamata District.

Figure 7 shows an example the dynamic hazard map, which displays landslide and debris flow. Each 1-km mesh polygon contains the date and time, latitude and longitude and three-hour cumulative rainfall value and the data can be 


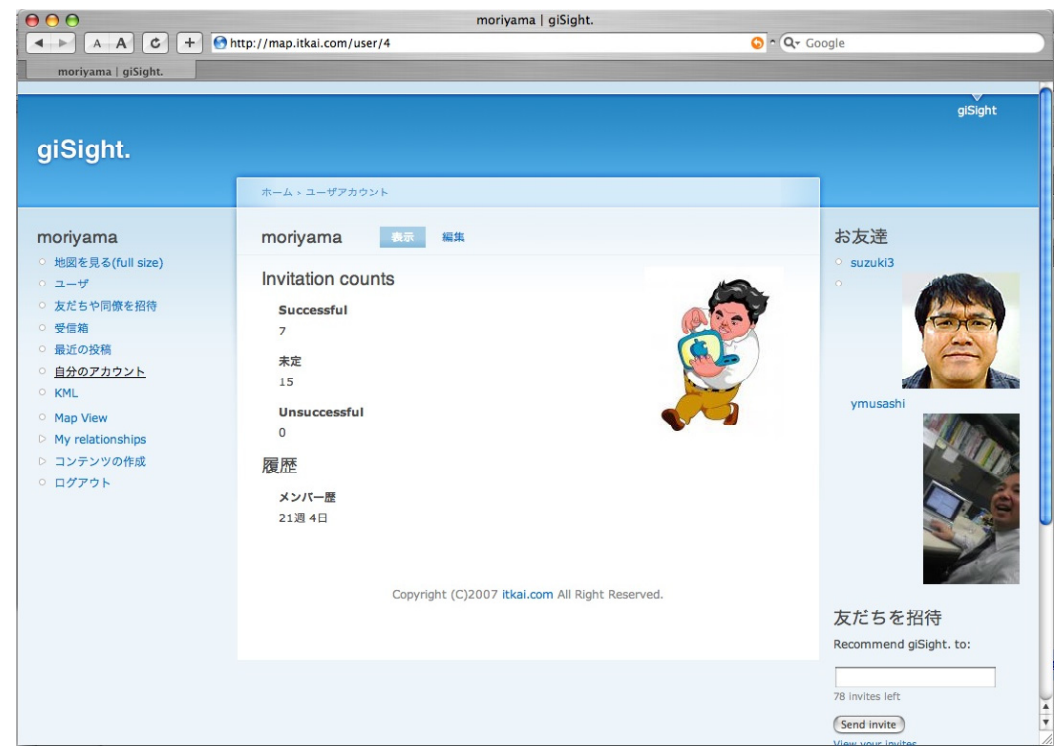

Figure 8: $\quad$ SNS photo list of friends.

accessed by clicking on the polygon. Figure 8 shows an example of the SNS function, a photo list of friends (registered users).

\section{Conclusion}

The giSight displays landslide and debris flow in real-time on a hazard map and provides the GIS data to residents using the SNS. giSight is able to provide quick delivery of hazard information as conditions indicate the potential for a landslide or debris flow. This system is not only useful for disaster prevention, but also enables the distribution of aerial information to local residents.

\section{References}

[1] Hirano, M., Iwamoto, M. and Harada, T., Study on the mechanism of occurrence of debris flow by artificial rainfall, Preprints of the annual meeting of JSCE, Tokyo, pp. 299-301, 1976 (in Japanese).

[2] Hirano, M., Hikida, M. and Moriyama, T., Field observation and prediction of the hydrograph of volcanic debris flow, Proceedings of the Fourth Congress of Asian and Pacific Regional Division of IAHR, Bankok, Vol.1, pp. 287-298, 1984

[3] Moriyama, T. \& Hikida, M., Rainfall Analysis of Debris Flow Occurrence in 2003, Minamata, Japan, Proc. of $2^{\text {nd }} A P H W$, Singapore, 2004

[4] eXist, exist.sourceforge.net

[5] Drupal, drupal.org

[6] Modestmaps, modestmaps.com

[7] Amazon S3, www.amazon.com/gp/browse.html?node=16427261 